\title{
Turizmin Ekonomik Büyümeye Etkisi: Turizme Dayalı Büyüme Hipotezinin Türkiye İçin Geçerliğinin ARDL Modeli ile Analizi*
}

\author{
The Impacts of Tourism on Economic Growth: Analyzing the Validity of the Tourism- \\ Led Growth Hypothesis for Turkey with the ARDL Model
}

\author{
Doç. Dr. Ethem Esen - Doç. Dr. Erkan Özata
}

\section{Öz}

Türkiye, önemli uluslararası turizm merkezlerinden biridir. Türkiye'de hükümetler, turizm sektörünü desteklemiş ve turizm sektörünün gelişimine öncelik vermişlerdir. Bu nedenle turizm Türkiye'de hızl büyüme gösteren bir hizmetler sektörü haline gelmiştir. Bu çalışmanin amacı Pesaran, Shin ve Smith tarafindan geliştirilen otoregresif dağıtılmış gecikme modelini (ARDL) kullanarak, Türkiye'de turizmin ekonomik büyüme üzerindeki etkisini araştırmak ve böylece turizme dayalı büyüme hipotezinin Türkiye için geçerli olup olmadiğın test etmektir. Analizde 2003:1-2015:4 dönemine ait çeyrek dönemlik reel Gayrisafi Yurtiçi Hasıla (GSYH), ülkeye gelen uluslararası turist sayısı ve reel döviz kuru (RER) verileri kullanılmıştır. Elde edilen sonuçlara göre turizmin Gayrisafi Yurtiçi Hasıla üzerinde hem kisa dönemde hem de uzun dönemde anlaml pozitif etkisi vardir. İkinci olarak Granger nedensellik testine Toda-Yamamoto yaklaşımı kullanılmış ve turizmden ekonomik büyümeye doğru tek yönlü bir nedensellik ilişkisi belirlenmiştir. Böylece çalışmadan elde edilen bulgular, turizme dayal büyüme hipotezinin Türkiye örneği için ampirik olarak desteklendiğini göstermektedir.

Anahtar Kelimeler: Turizm, Turizme Dayalı Büyüme Hipotezi, Ekonomik Büyüme, ARDL

\begin{abstract}
Turkey is one of the important international tourism destinations. Governments of Turkey supports and give priority to the development of tourism sector. Therefore, tourism has become a rapidly growing service sector in Turkey. The purpose of this study is to examine the impact of tourism on growth in Turkey and to test the validity of tourism-led growth hypothesis for Turkey through the Autoregressive Distributed Lag (ARDL) bounds testing approach developed by Pesaran, Shin and Smith. The analysis was carried out with quarterly data of Real GDP, volume of international tourist arrivals and Real Exchange Rate (RER) for the period from 2003:1 to 2015:4. The results reveals that tourism has a positive effect on Gross Domestic Product both in the short run and long run. Secondly the Toda-Yamamoto approach to Granger causality test is applied and a unidirectional causality running from tourism to economic growth is determined. So the findings show that the Tourism Led Growth Hypothesis is supported empirically in the case of Turkey.
\end{abstract}

Keywords: Tourism, Tourism-Led Growth Hypothesis, Economic Growth, ARDL

Doç. Dr. Ethem Esen, Anadolu Üniversitesi İİB, etheme@anadolu.edu.tr Doç. Dr. Erkan Özata, Anadolu Üniversitesi İ̇BF, eozata@anadolu.edu.tr

* Bu çalışma 18-20 Ağustos 2015 tarihlerinde İtalya’nın Torino şehrinde gerçekleştirilen EconWorld 2015@Torino Uluslararası İktisat Konferansında sunulan “Turizmin Ekonomik Büyümeye Etkisi: Türkiye Örneği” adlı bildirinin genişletilmiş halidir. 


\section{Giriş}

Turizm, ulusal ve bölgesel ekonomiler arasında dünyanın en büyük sanayisi ve iş yaratıcısı haline gelmiştir. Dünya Turizm Örgütüne (UNWTO) göre turizm dünyadaki toplam gelirin yaklaşık \%10'luk kısmını yaratan önemli bir ekonomik sektördür. Dünya çapinda bir ihracat kategorisi olarak turizm, gida ve otomotiv ürünleri ile yakıt ve kimyasallardan sonra üçüncü sırada yer almakta; hatta gelişmekte olan birçok ülkede, ihracat sektörleri içerisinde ilk sırada bulunmaktadır. Turizm günümüzde hizmetlerin uluslararası ticaretinde önemli bir kategori haline gelmiştir. Hizmet ihracatının yaklaşık \%30'luk kısmı turizm sektörü tarafından gerçekleştirilmektedir. Son dönemde turizm sürekli büyüyen ve çeşitlenen yapısı ile dünyanın en hızlı büyüyen ekonomik sektörlerinden birisi haline gelmiştir. Sanayileşmiş ve gelişmiş ülkelerde turizmin bu küresel yayılması ilişkili birçok sektörde de istihdam yaratarak iktisadi ve sosyal yaşama önemli katkılar sağlamıştır. Turizme yeni açılan bölgelerde yatırımlar artmış, yaratılan işler, kurulan şirketler, altyapı yatırımları sayesinde turizm sosyoekonomik gelişimin önemli bir aracı haline gelmiştir. Dünya turizminin uzun dönemdeki seyri incelendiğinde zaman zaman yaşanan şoklara rağmen, turizmin kesintisiz bir büyüme eğiliminde olduğunu söyleyebiliriz. Örneğin 1950 yılında küresel düzeyde 25 milyon olan uluslararası turist sayısı, 1980 yilında 278 milyona, 1995 yılında 527 milyona, 2014 yılında 1milyar 133 milyona çıkmıştır. Benzer bir eğilim uluslararası turizm gelirlerinde de görülmektedir. 1950 yılında 2 milyar Dolar olan uluslararası turizm gelirleri, 1980 yılında 104 milyar dolara, 1995 yılında 415 milyar dolara ve 2014 yilında 1 trilyon 245 milyar dolara çıkmıştır. Dünya turizm örgütünün uzun dönem beklentilerine göre 2010-2030 arası dönemde turist sayısı yılda \%3,3 artarak 2030 yılında 1,8 milyar turiste ulaşacaktır (UNWTO, Tourism Highlights, 2015).

Tablo 1'de uluslararası gelen turist sayısı bakımından en çok turist gelen ülkeler ve Tablo 2'de ise uluslararası turizm gelirleri açısından en çok gelir elde eden ülkeler sıralamaları verilmiştir. Tablo l’e göre, 2014 yılında uluslararası gelen turist sayısı açısından en fazla turist çeken ülke 83,7 milyon kişi ile Fransa'dır. Fransa'yı 74,8 milyon kişi ile Amerika Birleşik Devletleri (ABD); 65 milyon kişi ile İspanya ve 55,6 milyon kişi ile Çin takip etmektedir. Bu sıralama 2013 yllı içinde değişmemektedir. Uluslararası gelen turist sayısı bakımından Türkiye 2014 yılında 41,4 milyon kişi ile 6. sıradadır. Türkiye bu alanda Avrupảnın en çok ziyaret edilen dördüncü ülkesidir. 2014 yılında Türkiye'de, turist ziyaretlerinde bir önceki ylla göre yaklaşık \%5,6'lık bir artış gerçekleşmiştir. Tablo 2'ye göre, uluslararası turizm gelirinden parasal olarak en çok gelir elde eden ülkenin hem 2013 için hem de 2014 yll için ABD olduğu görülmektedir. Buna göre ABD uluslararası turizmden 2013 yilında 172,9 milyar dolar ve 2014 yılında 177,2 milyar dolar gelir elde etmiştir. 2014 yılı için ABD’yi sırasıyla; 65,2 milyar dolarlık gelir ile İspanya, 56,9 milyar dolar gelir ile Çin ve 55,4 milyar dolar gelir ile Fransa izlemektedir. Türkiyennin ise uluslararası turizm gelirleri siralamadaki yeri 34,3 milyar dolar ile 11. sıradır.

Tablo 1. Uluslararası Gelen Turist Sayısı (Milyon kişi)

\begin{tabular}{|l|c|c|}
\hline \multicolumn{1}{|c|}{ Ülkeler } & $\underline{\mathbf{2 0 1 3}}$ & $\underline{\mathbf{2 0 1 4}}$ \\
\hline 1. Fransa & 83,6 & 83,7 \\
2. ABD & 70,0 & 74,8 \\
3. İspanya & 60,7 & 65,0 \\
4. Çin & 55,7 & 55,6 \\
5. İtalya & 47,7 & 48,6 \\
6. Türkiye & 39,2 & 41,4 \\
7. Almanya & 31,5 & 33,0 \\
8. Ingiltere & 31,1 & 32,6 \\
9. Rusya Fed. & 28,4 & 29,8 \\
10. Meksika & 24,2 & 29,1 \\
\hline
\end{tabular}

Kaynak: UNWTO ve Türkiye'ye ilişkin veriler TÜiK'den sağlanmıştır.

Tablo 2. Uluslararası Turizm Gelirleri (Milyar Dolar)

\begin{tabular}{|l|c|c|}
\hline \multicolumn{1}{|c|}{ Ülkeler } & $\underline{\mathbf{2 0 1 3}}$ & $\underline{\mathbf{2 0 1 4}}$ \\
\hline 1. ABD & 172,9 & 177,2 \\
2. İspanya & 62,6 & 65,2 \\
3. Çin & 51,7 & 56,9 \\
4. Fransa & 56,7 & 55,4 \\
5. Makao (Çin) & 51,8 & 50,8 \\
6. İtalya & 43,9 & 45,5 \\
7. Ingiltere & 41,0 & 45,3 \\
8. Almanya & 41,3 & 43,3 \\
9. Tayland & 41,8 & 38,4 \\
10. Hong Kong (Çin) & 38,9 & 38,4 \\
11. Türkiye & 32,3 & 34,3 \\
\hline
\end{tabular}

Kaynak: UNWTO ve Türkiye’ye ilişkin veriler TÜİK'den sağlanmıştır. 


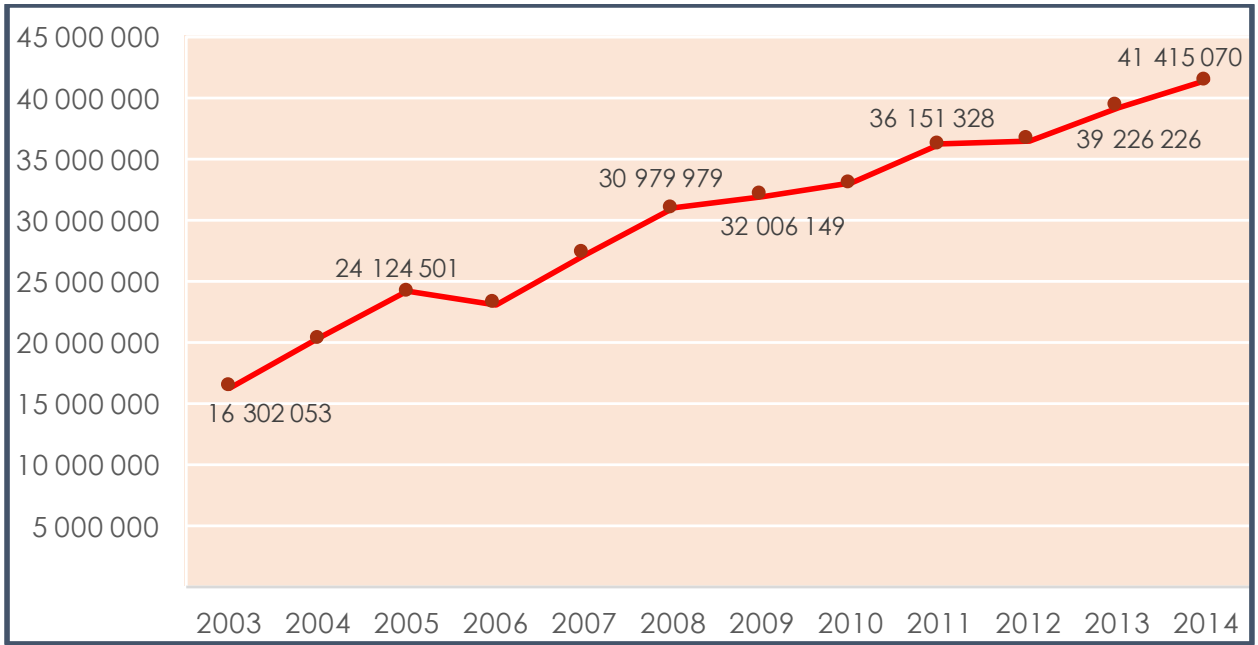

Kaynak: TÜIK

Şekil 1. Türkiye'ye Gelen Ziyaretçi Sayısı (2003-2014)

Şekil 1'de 2003-2014 yılları arası olan dönem için Türkiye’ye gelen ziyaretçilerin sayısı gösterilmiştir. Şekil l'e göre 2013 yılından 2014 yılına kadar olan dönemde Türkiye'ye gelen ziyaretçi sayısında 2006 yılı hariç devamlı bir artış görülmektedir. 2003 yılında Türkiye'ye gelen ziyaretçi sayısı 16.302.053 iken, 2014 yılına gelindiğinde bu sayı yaklaşık olarak 2,5 kattan daha fazla artarak 41.415.070 olmuştur.
Türkiye’ye gelen ziyaretçilerin geldiği döneme baktığ1mızda, havaların sıcak gittiği yaz aylarında gelen turist sayısında önemli bir artış olduğu görülmektedir. $\mathrm{Bu}$ durumu Şekil 2'ye bakarak görmek mümkündür. Şekil 2'de 2013 ve 2014 ylllarında Türkiye’ye aylara göre gelen ziyaretçi sayılarının grafiği gösterilmiştir. Şekle göre, hem 2013 yılında hem de 2014 yılında Türkiye’ye gelen ziyaretçi sayılarında Mayıs ayı itibariyle önemli

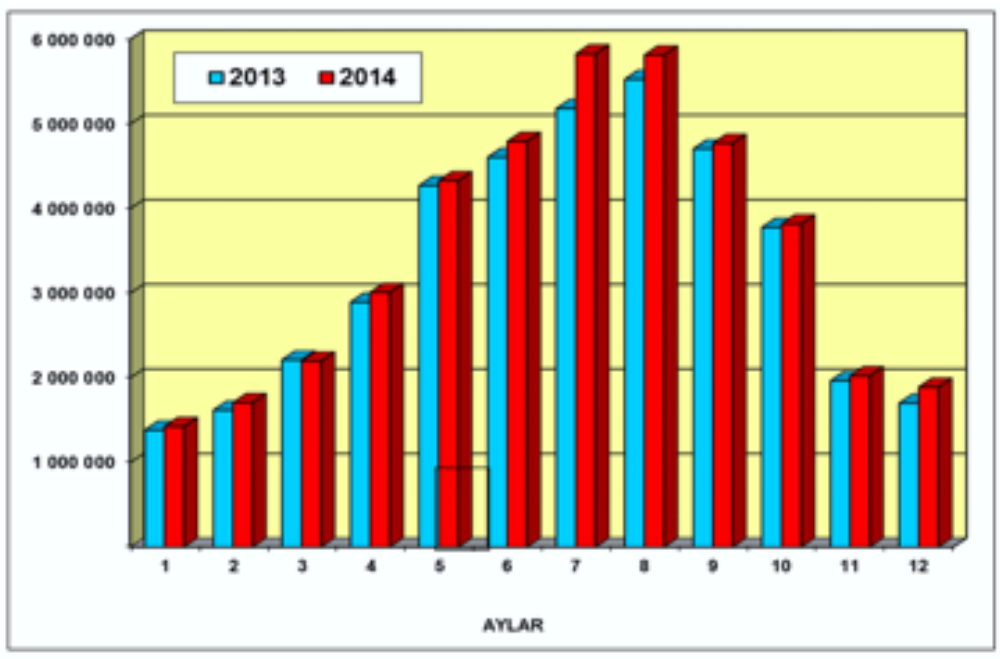

Kaynak: TÜİK

Şekil 2. Türkiye'ye Aylara Göre Gelen Ziyaretçiler (2013-2014) 
bir artış gözlenmekte, Temmuz ve Ağustos aylarında ülkeye gelen ziyaretçi sayısı zirve yapmakta ve Ekim ayına kadar olan dönem için önemli sayıda ziyaretçinin Türkiye’ye geldiği gözlenmektedir. Bu durumda, Türkiye’ye gelen ziyaretçilerin özellikle daha çok plaj turizmi amaciyla geldiklerini söylemek mümkündür.
Türkiye'ye gelen ziyaretçiler Türkiye’nin turizmden önemli miktarda döviz geliri sağlamasına katkıda bulunmaktadır. Böylece turizm sektörü ülkenin ekonomik büyümesine katkıda bulunan önemli bir sektör olarak ön plana çıkmaktadır. Şekil 3'de 2003-2014 yılları arası dönem için Türkiye’nin turizm gelirinin

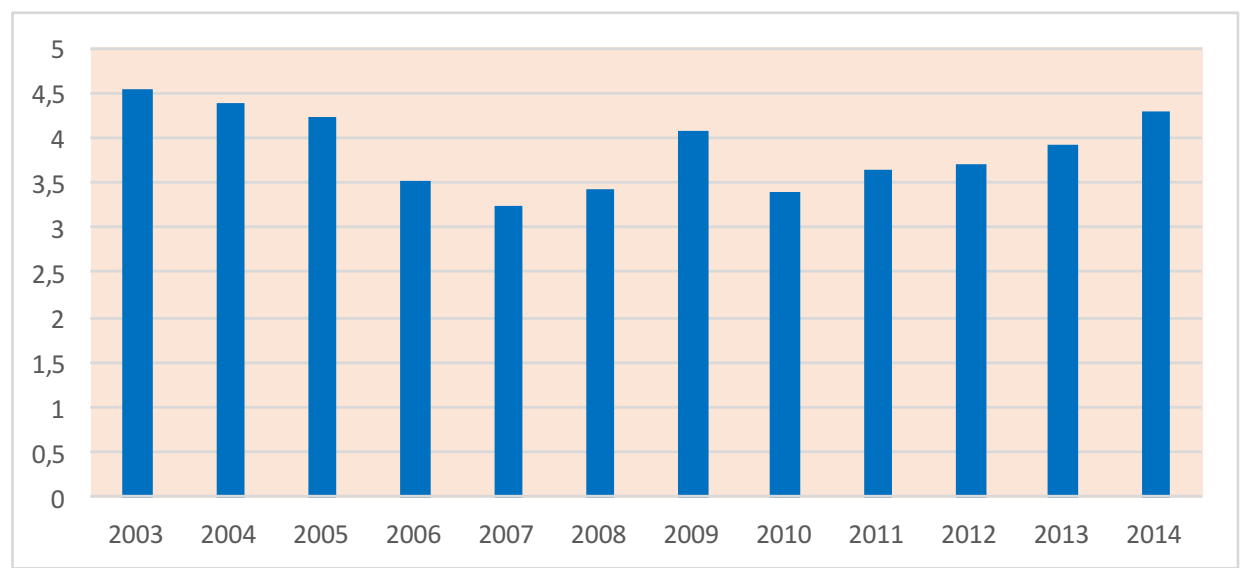

Kaynak: TÜİK

Şekil 3. Türkiye'nin Turizm Gelirinin GSYH'ye Oranı (\%) (2003-2014)

Gayrisafi Yurtiçi Hasılaya (GSYH) oranı gösterilmiştir. Şekil incelendiğinde, ilgili dönemde turizmin Türkiye'nin GSYH'sine katkısının yaklaşık olarak \%3,2 ile \%4,5 arasında değiștiği görülmektedir. 2007 y1lından 2014 yılına kadar olan dönemde ise, 2008 küresel krizinin etkilerinin görüldüğü 2009 yılından 2010 yılına geçen dönem hariç, Türkiye'nin turizm gelirlerinin GSYH'ye oranında devamlı bir artış olduğu Şekil 3'den izlenmekte ve bu oranın yaklaşık $\% 4,5$ ’lere çıktığg görülmektedir.

Uluslararası turizm ile ekonomik büyüme arasındaki ilişki araştırmacıların ilgi odağı olmuş ve ekonomik büyümenin ihracatın büyümesiyle de oluşabileceğini ifade eden ihracata dayalı büyüme hipotezi altında ele alınarak analiz edilmiştir. Bunu takiben, turizmin ekonomik büyümenin önemli bir belirleyicisi olduğunu ve turizmin ekonomik büyümeyi sağladığını ifade eden turizme dayalı büyüme hipotezi (TLGH), ihracata dayalı büyüme hipotezinden türetilmiştir
(Brida vd., 2014, s. 1; Katırcıoğlu, 2011, s. 422). İlgili literatürde uluslararası turizm ile ekonomik büyüme arasındaki ampirik çalışmalar hâlâ yeterli düzeyde olmadığı için, bu çalışmada bu konunun seçilmesi tercih edilmiştir, Dolayısıyla bu çalışmanın amacı, Autoregressive Distributed Lag (ARDL) sinır testi yaklaşımı ile Türkiye'de turizmin ekonomik büyüme üzerindeki etkisini incelemek ve böylece, turizme dayalı büyüme hipotezinin Türkiye için geçerli olup olmadığını test etmektir. Çalışmanın bu aşamadan sonraki planı şu şekilde olacaktır. Öncelikle literatürde turizme dayalı büyüme hipotezini inceleyen çalışmaların sonuçları kısaca özetlenecek, kullanılan yöntem ve elde edilen sonuçlar listelenecektir. Daha sonra bu çalışmada kullanılacak olan ARDL modeli kısaca anlatıldıktan sonra veri seti tanıtılacaktır. Bir sonraki bölümde ampirik bulgular sunulacaktır. Son olarak sonuç bölümünde önemli bulgular kısaca özetlendikten sonra politika önerilerine yer verilecektir. 
Tablo 3. Literatür Incelemesi

\begin{tabular}{|c|c|c|c|c|}
\hline Yazarlar & Dönem & Ülke & Yöntem & $\begin{array}{c}\text { Nedenselliğin } \\
\text { Yönü }\end{array}$ \\
\hline Corrie vd. (2013) & 2000-2010 Çeyrek & Avustralya & ARDL, Nedensellik & TUR↔Y \\
\hline Jackman (2012) & 1975-2010 Çeyrek & Barbados & Nedensellik & $\mathrm{TUR} \rightarrow \mathrm{Y}$ \\
\hline Brida vd. (2011) & 1965-2007 Yıllık & Brezilya & Eşbütünleşme, Nedensellik & $T U R \rightarrow Y$ \\
\hline Ahiawodzi (2013) & 1985-2010 Yıllık & Gana & Eşbütünleşme, Nedensellik & $T U R \rightarrow Y$ \\
\hline Akinboade ve Braimoh (2010) & 1980-2005 Yıllık & Güney Afrika & Eşbütünleşme, Nedensellik & $T U R \rightarrow Y$ \\
\hline Payne ve Mervar (2010) & 2000-2008 Çeyrek & Hırvatistan & Eşbütünleşme, Nedensellik & $\mathrm{Y} \rightarrow \mathrm{TUR}$ \\
\hline Mishra vd. (2011) & 1978-2009 Yıllık & Hindistan & Eşbütünleşme, VECM, Nedensellik & $\mathrm{TUR} \rightarrow \mathrm{Y}$ \\
\hline $\begin{array}{l}\text { Balaguer ve Cantavella-Jorda } \\
\text { (2002) }\end{array}$ & 1975-1997 Çeyrek & İspanya & Eşbütünleşme, Nedensellik & $T U R \rightarrow Y$ \\
\hline Cortes vd. (2010) & 1954-2000 Yıllık & $\begin{array}{l}\text { İspanya } \\
\text { İtalya }\end{array}$ & Eşbütünleşme, Nedensellik & $\begin{array}{c}\text { İspanya: TUR↔Y } \\
\text { İtalya: } T U R \rightarrow Y\end{array}$ \\
\hline Brida vd. 2009 & 1987-2007 Çeyrek & Kolombiya & Eşbütünleşme, Nedensellik & $T U R \rightarrow Y$ \\
\hline Oh (2005) & 1975-2001 Çeyrek & Kore & VAR, Nedensellik & $\mathrm{Y} \rightarrow \mathrm{TUR}$ \\
\hline Katırcıoğlu (2010) & 1977-2007 Yıllık & KKTC & ARDL, Nedensellik & $\mathrm{TUR} \rightarrow \mathrm{Y}$ \\
\hline Tang ve Abosedra (2014) & 1995-2010 Yıllık & Lübnan & ARDL, Nedensellik & $\mathrm{TUR} \rightarrow \mathrm{Y}$ \\
\hline Tang (2013) & 1970-2009 Yıllık & Malezya & ARDL, Nedensellik & $\mathrm{TUR} \leftrightarrow \mathrm{Y}$ \\
\hline Katırcıoğlu (2009a) & 1960-2006 Yıllık & Malta & ARDL, Nedensellik & TUR $\leftrightarrow Y$ \\
\hline Katırcıoğlu (2011) & 1960-2007 Yıllık & Singapur & ARDL, Nedensellik & $\mathrm{TUR} \rightarrow \mathrm{Y}$ \\
\hline Srinivasan vd. (2012) & 1969-2009 Yıllık & Sri Lanka & ARDL, Nedensellik & TUR $\rightarrow Y$ \\
\hline Jayathilake (2013) & 1967-2011 Yıllık & Sri Lanka & Eşbütünleşme, VECM, Nedensellik & $\mathrm{TUR} \rightarrow \mathrm{Y}$ \\
\hline Brida ve Risso (2009) & 1988-2008 Yıllık & Şili & Eşbütünleşme, Nedensellik & $\mathrm{TUR} \rightarrow \mathrm{Y}$ \\
\hline Kim vd. (2006) & 1971-2003 Çeyrek & Tayvan & Eşbütünleşme, Nedensellik & $T U R \leftrightarrow Y$ \\
\hline Belloumi (2010) & 1970-2007 Yıllık & Tunus & Eşbütünleşme, VECM, Nedensellik & $\mathrm{TUR} \rightarrow \mathrm{Y}$ \\
\hline Gunduz ve Hatemi-J (2005) & 1963-2002 Yıllık & Türkiye & Kaldıraçlı bootstrap nedensellik & $T U R \rightarrow Y$ \\
\hline Ongan ve Demiroz (2005) & 1980-2004 Çeyrek & Türkiye & Eşbütünleşme, VECM, Nedensellik & TUR↔Y \\
\hline Kaplan ve Çelik (2008) & 1963-2006 Yıllık & Türkiye & Eşbütünleşme, Nedensellik & $\mathrm{TUR} \rightarrow \mathrm{Y}$ \\
\hline Katırcıoğlu (2009b) & 1960-2006 Yıllık & Türkiye & ARDL, Eşbütünleşme & Yok \\
\hline Zortuk (2009) & 1990-2008 Çeyrek & Türkiye & Eşbütünleşme, VECM, Nedensellik & $\mathrm{TUR} \rightarrow \mathrm{Y}$ \\
\hline Arslantürk vd. (2011) & 1963-2006 Yıllık & Türkiye & VECM, Nedensellik & Yok \\
\hline Husein ve Kara (2011) & 1964-2006 Yıllık & Türkiye & Eşbütünleşme, VECM, Nedensellik & $T U R \rightarrow Y$ \\
\hline Işık (2012) & 1990-2008 Yıllık & Türkiye & Eşbütünleşme, VECM, Nedensellik & $\mathrm{TUR} \rightarrow \mathrm{Y}$ \\
\hline Coşkun ve Özer (2014) & 1992-2014 Çeyrek & Türkiye & Eşbütünleşme-VECM-Nedensellik & TUR↔Y \\
\hline Ertugrul ve Mangir (2015) & 1998-2011 Çeyrek & Türkiye & ARDL, Eşbütünleşme, Nedensellik & $\mathrm{TUR} \rightarrow \mathrm{Y}$ \\
\hline Kreishan (2011) & 1970-2009 Yıllık & Ürdün & Eşbütünleşme, VECM, Nedensellik & $T U R \rightarrow Y$ \\
\hline Dritsakis (2004) & 1960-2000 Çeyrek & Yunanistan & Eşbütünleşme, VECM, Nedensellik & TUR↔Y \\
\hline Kasimati (2011) & 1960-2010 Yıllık & Yunanistan & Eşbütünleşme, VECM, Nedensellik & Yok \\
\hline
\end{tabular}




\section{Literatür}

Literatürde turizmin ekonomik büyümeye etkisi üzerine ve turizme dayalı büyüme hipotezi (TLGH) üzerine farklı ülkeler ve ülke grupları için çeşitli çalışmalar mevcuttur. Aynı zamanda bu çalışmalarda uygulanan ekonometrik yöntemler için de farklılıklar söz konusudur. Literatürde turizme dayalı büyüme hipotezi üzerine olan ilk çalışma, Balaguer ve CantavellaJordảnın (2002) İspanya için yaptığı çalışmadır (Brida vd., 2014, s. 1). Çalışmada uluslararası turizm gelirleri ile ekonomik büyüme arasındaki ilişki analiz edilmiştir. Çalışmada 1975:1 ile 1997:1 arasındaki dönem için Johansen eşbütünleşme yöntemi ve Granger nedensellik testi kullanılmıştır. Elde edilen sonuçlar TLGH hipotezinin İspanya için geçerliliğini ortaya koymuştur.

Tablo 3'de turizme dayalı büyüme hipotezi üzerine yapılan ülke çalışmalarından birçoğu uygulandığı dönem, yöntem ve elde edilen nedensellik ilişkisi açısından ayrıntılı olarak gösterilmiştir. Ülkeler üzerine yapılan çalışmaların çoğu, analiz yöntemi olarak vektör hata düzeltme modelini (VECM) seçmiş ve bunlara eşbütünleşme ve nedensellik analizlerini uygulamıştır. Daha az sayıda çalışma ise ARDL sınır testi yaklaşımını analiz yöntemi olarak seçmiştir. Tablo 3'de gösterilen literatüre ilişkin ampirik çalışmaların çoğunda turizmden ekonomik büyümeye doğru nedensellik ilişkisinin varlığı ortaya konulmuştur (Örneğin, Corrie vd., 2013; Jackman, 2012; Brida vd., 2011; Mishra vd.,2011; Balaguer ve Cantavella-Jorda, 2002; Cortes vd., 2010; Katırcıoğlu, 2009a, 2009b, 2010, 2011; Srinivasan vd., 2012; Brida ve Risso, 2009; Gunduz ve Hatemi-J, 2005; Coşkun ve Özer, 2014; Dritsakis, 2004 gibi). Bu da turizme dayalı büyüme hipotezinin bu ülkeler için geçerli olduğu sonucunu göstermektedir. Bununla birlikte az sayıda çalışma ise turizme dayalı büyüme hipotezinin geçerliliği üzerine bir bulgu elde edememişlerdir (Örneğin, Payne ve Mervar, 2010; Oh, 2005; Katırcıoğlu, 2009b; Arslantürk vd., 2011 ve Kasimati, 2011 gibi). Bu çalışmalardan Oh (2005) Kore ekonomisi için, Payne ve Mervar (2010) Hırvatistan için turizm ile ekonomik büyüme arasında herhangi bir ilişki bulamamışken; sadece kısa dönemde ekonomik büyümeden turizme doğru tek yönlü bir nedensellik ilişkisi elde etmişlerdir. Türkiye için yapılan ampirik çalışmalara bakıldığında, çalışmaların çoğu turizme dayalı büyüme hipotezinin Türkiye için geçerliliği ortaya koyan sonuçlar elde etmiş̧ir (Gunduz ve Hatemi-J, 2005; Ongan ve Demiroz, 2005; Kaplan ve Çelik, 2008; Zortuk, 2009; Husein ve Kara, 2011; Işık, 2012; Coşkun ve Özer, 2014; Ertugrul ve Mangir, 2015). Bununla birlikte Katırcıoğlu (2009b) ve Arslantürk vd. (2011) turizme dayalı büyüme hipotezinin Türkiye için geçerli olduğuna dair herhangi bir bulgu elde edememişlerdir.

\section{ARDL Modeli ve Veri Seti}

Değişkenler arasındaki uzun dönem ilişkilerin incelenmesinde eşbütünleşme yöntemi kullanılmaktadır. $\mathrm{Bu}$ testlerden geleneksel olarak ifade edebileceğimiz ve en sık kullanılanlar Engle-Garnger (1987), Johansen-Juselius (1990) ve Johansen $(1988,1991)$ testleridir. Pesaran ve Shin (1999) ile Pesaran vd. (2001) tarafından geliştirilen ARDL sınır testi yönteminin diğer geleneksel eşbütünleşme yaklaşımlarına göre bazı avantajları vardır. Diğer eşbütünleşme yöntemlerinin aksine ARDL modelinde kullanılan değişkenlerin hepsinin aynı dereceden bütünleşik olması gerektiği gibi sınırlayıcı bir varsayım bulunmamaktadır. Dolayısıyla I(0) ve I(1) değiş̧kenler birlikte kullanılabilmektedir. Ancak sınırlayıcı bir koşul olarak hiçbir değişkenin ikinci ya da daha yüksek dereceden bütünleşik olmaması gerekmektedir (Çağlayan, 2006, s. 427). Bu yaklaşım ile durağan olmayan serilerden kaynaklanan problemler büyük ölçüde giderilmektedir. Ayrıca analizde yer alan değişkenler farklı gecikme uzunluklarına sahip olabilmektedir. VAR modelinde olduğu gibi değişkenlerin tümünün aynı gecikme uzunluğuna sahip olması gerekmez. ARDL modelinin bir başka avantajı da kısa ve uzun dönem parametrelerinin birlikte tahmin edilebilmesidir.

$$
\Delta L Y_{t}=\alpha_{0}+\sum_{i=1}^{m} \alpha_{1} \Delta L Y_{t-i}+\sum_{i=0}^{m} \alpha_{2} \Delta L T U R_{t-i}+\sum_{i=0}^{m} \alpha_{3} \Delta R E R_{t-i}+\lambda_{1} L Y_{t-1}+\lambda_{2} L T U R_{t-1}+\lambda_{3} R E R_{t-1}+\varepsilon_{t}
$$


Modele doğrusal dönüşüm uygulayarak uzun dönem bilgisini kaybetmeden kısa dönem ve uzun dönem ilişkilerini birleştiren bir Hata Düzeltme Modeli elde etmeyi mümkün kılar. Bir başka önemli avantaj da küçük örneklemlere de uygulanabilmesidir. Sınırlı gözlem sayısına sahip olunduğu durumlarda bile tutarlı ve güvenilir sonuçlar vermektedir.

ARDL modeli belirtilen avantajlarından dolayı tercih edilmiş ve model (1) oluşturulmuştur.

Burada $L Y$ Reel Gayrisafi Yurt içi Hasılanın doğal logaritması, LTUR gelen turist sayısının doğal logaritması, RER ise TUFE bazlı Reel Efektif döviz kurudur. Eşitliğin sağ tarafında yer alan $\lambda_{1}, \lambda_{2}$ ve $\lambda_{3}$ katsayıları değişkenler arasındaki uzun dönem ilişkiyi gösterirken, $\alpha_{1}, \alpha_{2}$ ve $\alpha_{3}$ katsayıları değişkenler arasındaki kısa dönem dinamik ilişkileri ifade etmektedir. $\Delta$ birinci fark işlemcisi, $\alpha_{0}$ sabit terim, $\varepsilon_{\mathrm{t}}$ ise beyaz gürültü hata terimidir.

Kısa ve uzun dönem dinamiklerin ARDL sınır testi yaklaşımı ile incelenmesi birkaç aşamadan oluşan bir süreci gerektirmektedir. Birinci aşamada Model (1) OLS yöntemi ile tahmin edilir ve değişkenler arasındaki uzun dönem ilişkinin incelenebilmesi için gecikmeli değişkenlerin katsayılarının birlikte anlamlılığ1nın sınandığı bir F testi yapılır. Sıfır hipotezi $H_{0}: \lambda_{1}=$ $\lambda_{2}=\lambda_{3}=0$ şeklinde olup değişkenler arasında uzun dönem ilişkinin ya da kısaca eşbütünleşmenin olmadığını ifade etmektedir. Alternatif hipotez ise $H_{1}: \lambda_{1}$ $\neq \lambda_{2} \neq \lambda_{3} \neq 0$ şeklindedir. Hesaplanan $\mathrm{F}$ istatistiğinin örnek değeri Pesaran vd. (2001) tarafından belirlenen üst ve alt sınır değerleri ile karşılaştırılır. Eğer hesaplanan $\mathrm{F}$ istatistiğinin örnek değeri tablo alt sınır değerinden küçükse, eşbütünleşmenin olmadığını ifade eden sifır hipotezi reddedilmez. Ancak hesaplanan F istatistiğinin örnek değeri, tablo üst sınır değerinden büyükse, sıfır hipotezi reddedilir ve modelde yer alan değişkenler arasında uzun dönem bir ilişkinin varlığ belirlenir. Eğer hesaplanan değer alt ve üst sınır değerleri arasında ise karar verilemez.

Eşbütünleşme ilişkisi belirlendikten sonra ikinci aşamada Hannan Quinn Kriteri, Akaike Bilgi Kriteri

$$
L Y_{t}=\alpha_{0}+\sum_{i=1}^{m} \alpha_{1} \Delta L Y_{t-i}+\sum_{i=0}^{m} \alpha_{2} \Delta L T U R_{t-i}+\sum_{i=0}^{m} \alpha_{3} \Delta R E R_{t-i}+\varphi E C M_{t-1}+\varepsilon_{t}
$$

(AIC), Schwarz Kriteri (SBC) gibi model seçim kriterleri kullanılarak değişkenler için uygun gecikme uzunlukları belirlenir. ARDL (p,q,r) şeklinde belirlenen modelde $p$ ilk değişkenimiz olan LY'nin gecikme uzunluğu, q ikinci değişken olan LTUR'un gecikme uzunluğu, $r$ ise üçüncü değişken olan RER'nin gecikme uzunluğudur.

Üçüncü aşamada Model 2 ile belirlenen hata düzeltme modeli tahmin edilir.

Burada $\alpha_{1}$, $\alpha_{2}$ ve $\alpha_{3}$ modeli dengeye getiren kısa dönem dinamik katsayılardır. $E C M$ hata düzeltme terimi, katsayısı $\varphi$ ise kısa dönemdeki bir şok sonucunda modelin tekrar uzun dönem dengesine dönme ve ayarlanma hızını gösteren katsayıdır. Bu katsayının negatif ve istatistiksel olarak anlamlı olması gerekir.

Tahmin edilen modelin istikrarlı olup olmadığını belirlemek için Pesaran ve Pesaran (1987) Brown vd.
(1975) tarafından geliştirilen CUSUM ve CUSUMSQ testlerinin kullanılmasını önermişlerdir. CUSUM ve CUSUMSQ istatistikleri ardışık olarak yinelenir ve kırılma noktalarına karşı işaretlenir. Yinelemeli parametre tahminlerinin grafiklerinin görsel olarak incelenmesi yapısal kırılma ya da modelin istikrarı konusunda bilgiler verir. CUSUM ve CUSUMSQ istatistikleri \%5 anlam düzeyinde çizilen kritik sınırlar arasında kalıyorsa modelin istikrarlı olduğunu ifade eden sıfır hipotezi reddedilmez.

Değişkenler arasındaki nedensellik ilişkilerinin yönünü belirlemek amacıyla Toda-Yamamoto yaklaşımı ile Granger nedensellik testi uygulanabilir. Granger (1988) tarafından önerildiği gibi dinamik Granger nedenselliği uzun dönem eşbütünleşme ilişkisinden elde edilen vektör hata düzeltme modelinden elde edilebilir. Granger (1969) tarafından önerilen ve eşbütünleşme ilişkisi bulunmasına rağmen hata düzeltme terimi kullanılmadan yapılan nedensellik testle- 
ri belirleme hatası ve sahte regresyon gibi sorunlar yaratabilir. Engle ve Granger’a (1987) göre durağan olmayan iki serinin doğrusal bileşimleri durağansa yani aralarında eşbütünleşme ilişkisi varsa, standart Granger nedensellik testi sonuçları geçerli sonuçlar vermez.

$\mathrm{Bu}$ sorunlara çözüm üretmek amacıyla Toda ve Yamamoto (1995) ve Dolado ve Lutkepohl (1996), VAR modeline dayanan değiştirilmiş bir Wald test istatistiği (MWALD) geliştirmişlerdir. Bu yöntemle duraganlık ve eşbütünleşme ile ilgili ön testler yapılmadan nedensellik testi yapılabilmektedir. Toda Yamamoto yaklaşımında modelde yer alan değişkenlerin maksimum bütünleşme dereceleri (dmax) belirlenir. Örneğin modelde kullanılan bir değişken $\mathrm{I}(0)$ ve iki değişken $\mathrm{I}(1)$ ise maksimum bütünleşme derecesi 1 olur. Daha sonra serilerin düzey değerleri ile kısıtsız bir VAR modeli tahmin edilerek uygun gecikme uzunluğu model seçim kriterlerinden yararlanılarak tespit edilir. Uygun modelin VAR(P) olduğunu var-

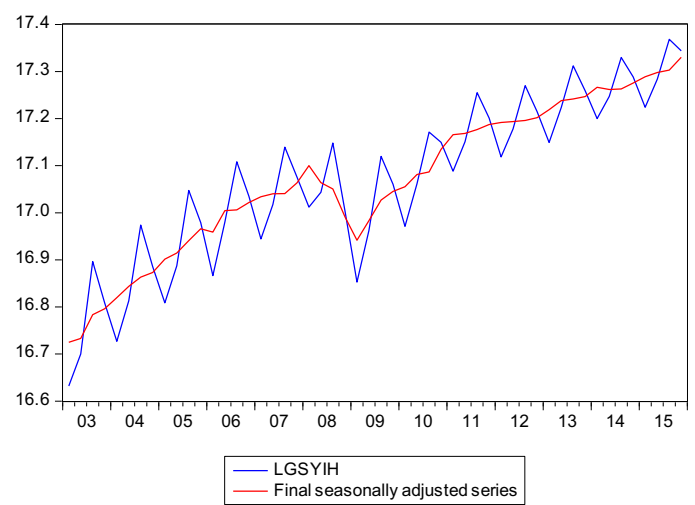

Şekil 4. Zaman Serisi Grafikleri

önemli bir değişken olduğu için, bu nedenle çalışmada dikkate alınmıştır. TUR ise ülkemize gelen turist sayısıdır ve Türkiye İstatistik Kurumu, turizm istatistiklerinden derlenmiştir. Gayrisafi Yurtiçi Hasıla ve turist sayıları mevsimsel etkiler içerdiğinden TramoSeats yöntemi ile mevsimsellikten arındırılmış doğal logaritmaları ile kullanılmıştır. Modelde yer alan $L Y$ GSYH'nin doğal logaritması, LTUR gelen turist sayısının doğal logaritmasıdır. Doğal logaritması alınmış seriler ile mevsimsellikten arındırılmış serilerin zaman serisi grafikleri Şekil 4'te sunulmaktadır. sayalım. Son olarak VAR $(\mathrm{P}+\mathrm{dmax})$ modeli tahmin edilerek VAR Granger nedensellik/Blok dişsallık testi uygulanir. VAR $(\mathrm{P}+\mathrm{dmax})$ modelinden hesaplanan MWALD test istatistiği asimptotik ki-kare dağılımına sahiptir. Test istatistiğinin örnek değeri tablo kritik değeri ile karşılaştırılarak nedenselliğin olmadığını ifade eden sıfır hipotezinin reddedilip reddedilmeyeceği belirlenir.

Analizde 2003 yılının birinci çeyreği ile 2015 yılının dördüncü çeyreği arası üçer aylık veriler kullanılmıştır. Y sabit (1998) fiyatlarla Gayri Safi Yurtiçi Hasılayı ifade etmekte olup Merkez Bankası Elektronik Veri Dağıtım sisteminden elde edilmiştir. Reel GSYH verisi ekonomik büyümenin hesaplanmasında kullanılmıştır. RER ise TÜFE Bazlı Reel Efektif Döviz Kurudur $(2003=100)$ ve Türkiye Cumhuriyeti Merkez Bankası Elektronik Veri Dağıtım sisteminden elde edilmiştir. Döviz kurları, uluslararası turizmi ve uluslararası turizmin reel gelir ile olan ilişkisini etkileyen

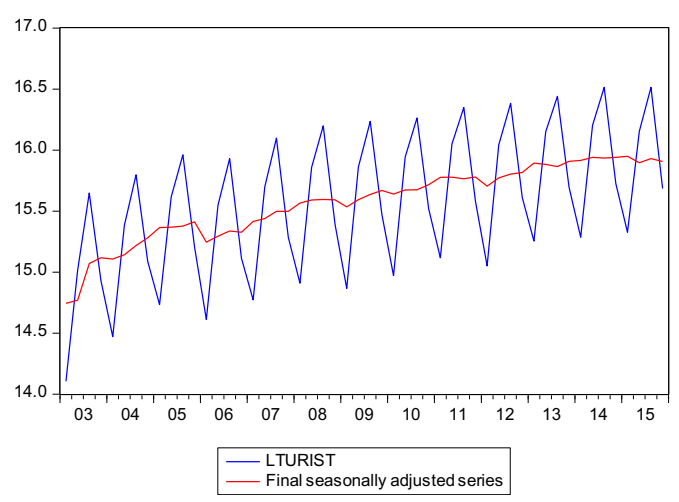

\section{Ampirik Bulgular}

ARDL modeli tahmin edilmeden önce serilerin durağanlık durumları ve bütünleşme dereceleri Augmented Dickey Fuller (ADF) ve Phillips Perron birim kök testleri kullanılarak araştırılmıştır. Bunu yapmaktaki amacımız serilerin hiçbirisinin I(2) olmadığından emin olmaktır. Çünkü Pesaran vd. (2001) tarafından sağlanan kritik F değerleri sadece değişkenlerin I(0) ve I(1) oldukları durumlarda geçerlidir. Birim kök testleri olan ADF ve PP arasındaki temel fark, hata terimlerinde bulunması muhtemel otokorelasyonu 
Tablo 4. ADF ve PP Birim Kök Testi Sonuçları

\begin{tabular}{|c|c|c|c|c|c|}
\hline & Değişkenler & \multicolumn{2}{|c|}{ Düzey Değerleri } & \multicolumn{2}{|c|}{ 1. Farkları } \\
\hline Test & & ADF & PP & ADF & PP \\
\hline İstatistiği & $\mathrm{LY}$ & $-3,086(1)$ & $-2,578(2)$ & $-5,463^{*}(0)$ & $-5,428 *(0)$ \\
\hline (Sabitli \& & RER & $-2,789 * * *(0)$ & $-2,9550 * *(2)$ & & \\
\hline Trendli) & LTUR & $-3,246(0)$ & $-2,7328(2)$ & $-7,037^{*}(10)$ & $-7,76 *(0)$ \\
\hline
\end{tabular}

Parantez içindeki değerler ADF için gecikme uzunluklarını, PP için bant genişliğini ifade etmektedir. Gecikme uzunluğunun seçiminde Schwarz Bilgi Kriteri (SIC) kullanılmıştır. Bant genişliği ise Bartlett Kernel modeli kullanılarak Newey West'e göre belirlenmiştir.

*\% 1 anlam düzeyinde, ${ }^{* *} \% 5$ anlam düzeyinde, ${ }^{* *} \% 10$ anlam düzeyinde anlamlıllğ ifade etmektedir.

analiz etme noktasındaki farklılıklardır (Kostakoğlu, 2016, s. 64). Testlerin sonuçları Tablo 4’te sunulmaktadir.

$\mathrm{ADF}$ ve $\mathrm{PP}$ birim kök testlerinin sonuçlarına göre milli gelir (LY) ve turist sayısı (LTUR) serilerinin I(1), Reel döviz kuru serisinin ise I(0) olduğu sonucuna ulaşılmıştır. Hiçbir değişkenimizin I(2) olmadığ belirlendikten sonra ARDL modeli tahmin edilebilir.
Akaike Bilgi Kriteri (AIC) kullanılarak uygun modelin ARDL $(8,5,3)$ modeli olduğu belirlenmiștir. Buna göre LY'nin 8 gecikmesi, LTUR'un 5 gecikmesi ve RER'nin 3 gecikmesi modele dahil edilmiştir. Akaike Bilgi Kriterine göre uygun modellerin sıralaması Şekil 5'de gösterilmektedir.

Turizm ve ekonomik büyüme arasında eşbütünleşme ilişkisini araştırmak için yapılan sınır testi sonuçları

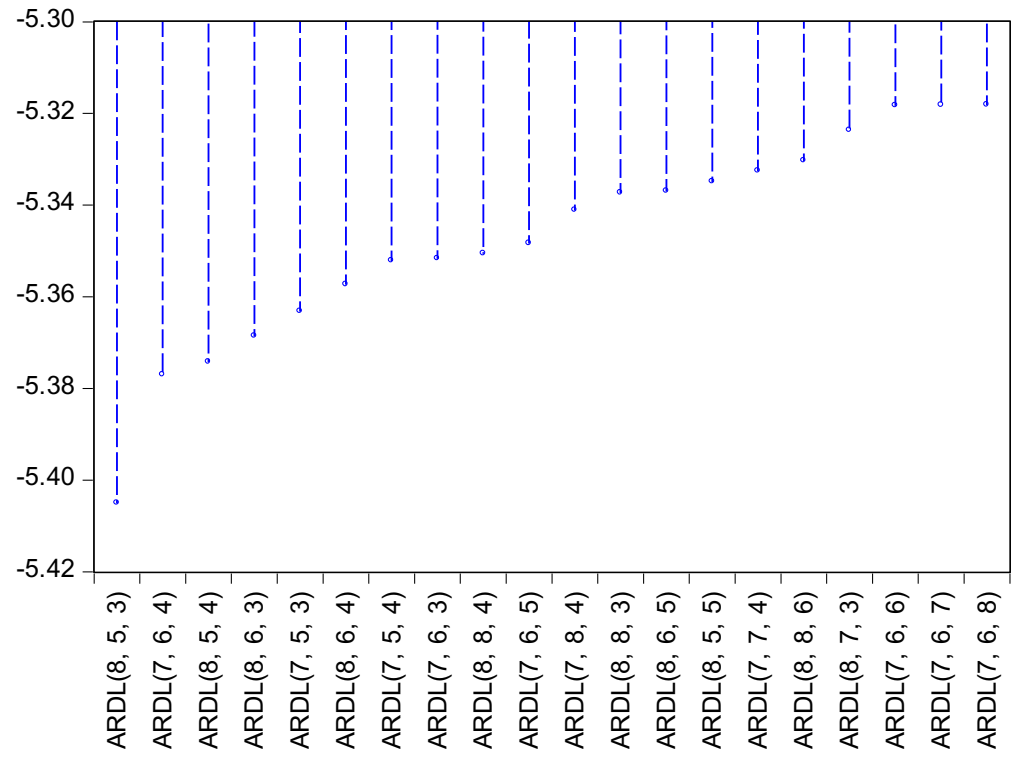

Şekil 5. Akaike Bilgi Kriterine göre en iyi 20 Model 
Tablo 5. Eşbütünleşme için Sınır Testi Sonuçları

\begin{tabular}{|c|c|c|}
\hline \multirow[t]{2}{*}{ Hesaplanan $\mathrm{F}$ istatistiği: 7,58} & \multicolumn{2}{|c|}{ Kritik Değerler } \\
\hline & Alt Sinır $I(0)$ & Üst Sinır $I(1)$ \\
\hline$\% 1$ anlam düzeyi & 4,99 & 5,85 \\
\hline$\% 5$ anlam düzeyi & 3,88 & 4,61 \\
\hline$\% 10$ anlam düzeyi & 3,38 & 4,02 \\
\hline
\end{tabular}

ile Pesaran vd. (2001) tarafından hesaplanan kritik değerler Tablo 5'de verilmektedir. Buna göre hesaplanan $F$ istatistiğinin örnek değeri olan 7.58; \%5 anlam düzeyindeki tablo üst sınır değeri olan 4,61'den büyük olduğundan, eşbütünleşme ilişkisi bulunmad1ğını ifade eden sıfır hipotezi reddedilerek, Türkiye'de turizm ve ekonomik büyüme arasında uzun dönem eşbütünleşme ilişkisi bulunduğu sonucuna ulaşılır.
Değişkenler arasında eşbütünleşme ilişkisi belirlendikten sonra, Akaike Bilgi Kriterine göre seçilen $\operatorname{ARDL}(8,5,3)$ modeline ait uzun dönem katsayllar belirlenmiş ve sonuçlar Tablo 6'da sunulmuştur. Buna göre turizmin tahmin edilen katsayısı pozitif ve $\% 1$ anlam düzeyinde anlamlıdır. Diğer faktörler sabitken gelen turist sayısındaki \%1'lik artış, uzun dönemde GSYH'yi \%0.937 arttıracaktır. Bu ampirik bulgu

Tablo 6. ARDL $(8,5,3)$ Modeline Ait Uzun Dönem Katsayılar

\begin{tabular}{lccc}
\hline \multicolumn{2}{c}{ Bağımlı Değişken: $L Y$} & \\
\hline Değişkenler & Katsayılar & t istatistiği & Prob. Değeri \\
\hline LTUR & 0,9370 & 3,9290 & 0,0006 \\
RER & 0,0039 & 3,3382 & 0,0027 \\
@ TREND & 0,0269 & 6,2995 & 0,0000 \\
\hline
\end{tabular}

Türkiye'de turizmin ekonomik büyüme üzerinde pozitif etkisi olduğunu göstermektedir.

ARDL modelinden elde edilen kısa dönem katsay1lar ve hata düzeltme terimine ait katsayı Tablo 7'de sunulmuştur. Gelen turist sayısını temsil eden LTUR değişkenine ait gecikmeli katsayılar da uzun dönemde tahmin edilen katsayı gibi pozitif bulunmuştur ancak büyüklük olarak uzun dönemde elde edilen değer daha yüksektir. Ayrıca turizmin ekonomik büyüme üzerindeki etkisi ikinci gecikmeden sonra anlamlı hale gelmektedir. Bu sonuçlara göre turizmin ekonomik büyüme üzerindeki etkisinin uzun dönemde daha fazla olduğunu söyleyebiliriz.
Modele ait kısa dönem dinamikleri incelemenin bir başka önemli çıtısı da Hata Düzeltme Terimine ait katsayının hesaplanmasıdır. Gecikmeli hata düzeltme terimi $E C M_{t-1}$ ve katsayısı Tablo 7'nin ilk bölümünün en alt satırında yer almaktadır. Hata düzeltme katsayısı negatiftir ve $\% 1$ anlam düzeyinde anlamlıdır (Prob=0,0000). Hata düzeltme teriminin katsayısı kısa dönemdeki bir şok sonrasında uzun dönem dengesine dönüş ve ayarlanma hızını gösterir. Burada hata düzeltme katsayısı olan -0,48'i şöyle yorumlayabiliriz. Bir önceki dönemde oluşan şok sonrasında milli gelirde yaşanan dengesizliğin \%48'lik kısmı cari dönemde kapanarak uzun dönemdeki dengesine doğru tekrar hareket edecektir. Bu değer oldukça hızlı bir ayarlanma olduğunu göstermektedir. 
Tablo 7. ARDL Modelinin Hata Düzeltme Gösterimi

\begin{tabular}{|c|c|c|c|}
\hline \multirow[b]{2}{*}{ Değişken } & \multicolumn{3}{|c|}{ Bağımlı Değişken : $L Y$} \\
\hline & Katsayı & t-istatistiği & Prob. \\
\hline$\Delta L Y_{t-1}$ & 0,61411 & $4,581364^{*}$ & 0,0001 \\
\hline$\Delta L Y_{t-2}$ & 0.301495 & $2.078745^{\star *}$ & 0.0485 \\
\hline$\Delta L Y_{t-3}$ & 0.146270 & 1.051239 & 0.3036 \\
\hline$\Delta L Y_{t-4}$ & -0.063256 & -0.517470 & 0.6096 \\
\hline$\Delta L Y_{t-5}$ & 0.135250 & 1.177058 & 0.2507 \\
\hline$\Delta L Y_{t-6}$ & 0.346724 & $3.182197^{*}$ & 0.0040 \\
\hline$\Delta L Y_{t-7}$ & 0.195982 & 1.694213 & 0.1032 \\
\hline$\triangle L T U R$ & 0.016867 & 0.286859 & 0.7767 \\
\hline$\Delta L T U R_{t-1}$ & 0.083324 & 1.188665 & 0.2462 \\
\hline$\Delta L T U R_{t-2}$ & 0.187437 & $2.710816^{\star *}$ & 0.0122 \\
\hline$\Delta L T U R_{t-3}$ & 0.203656 & $2.871452^{*}$ & 0.0084 \\
\hline$\Delta L T U R_{t-4}$ & 0.268244 & $4.485119^{*}$ & 0.0002 \\
\hline$\triangle R E R$ & 0.001819 & $3.979830 *$ & 0.0006 \\
\hline$\Delta R E R_{t-1}$ & -0.000557 & -1.071067 & 0.2948 \\
\hline$\Delta R E R_{t-2}$ & -0.001697 & $-3.428071^{*}$ & 0.0022 \\
\hline$C$ & 14.913426 & $5.841393^{*}$ & 0.0000 \\
\hline$E C M_{t-1}$ & -0.488420 & $-5.838976^{*}$ & 0.0000 \\
\hline \multicolumn{4}{|c|}{$E C M=L Y-0,9370 L T U R-0,0039 R E R-0,0269 @ T R E N D$} \\
\hline$R^{2}=0,9927$ & \multicolumn{2}{|c|}{$\mathrm{F}=172,43$} & Durbin Watson $d=1,93$ \\
\hline \multicolumn{4}{|l|}{ Tanısal Testler } \\
\hline \multicolumn{4}{|c|}{ Otokorelasyon LM Testi $=0,047(0,828)$} \\
\hline \multicolumn{4}{|c|}{ Değişen Varyans White Testi $=21,24(0,3233)$} \\
\hline \multicolumn{4}{|c|}{ JB Normallik Testi=2,69 $(0,2597)$} \\
\hline RESET T & $0,0808)$ & & \\
\hline
\end{tabular}

*\%1 anlam düzeyinde anlamlılığ ${ }_{1}^{* *} \% 5$ anlam düzeyinde anlamlılığ 1 ifade etnektedir.

Yapılan tanısal testlerde modelde ekonometrik herhangi bir sorun olmadığı görülmüștür. Breusch Godfrey LM testi sonuçlarına göre modelde otokorelasyon olmadığını ifade eden sıfır hipotezini kabul ederiz. White değişen varyanslılık testine göre de sabit varyansı ifade eden sıfır hipotezi kabul edilmek- tedir. Jarque Bera Normallik testine göre hata terimlerinin normal dağıldığını ifade eden sıfır hipotezi kabul edilmektedir. Ramsey RESET Testi sonuçlarına göre ise modelde belirleme hatası yapılmadığını ifade eden sıfir hipotezi \%5 anlam düzeyinde kabul edilmektedir. Kısaca model doğru belirlenmiştir. 


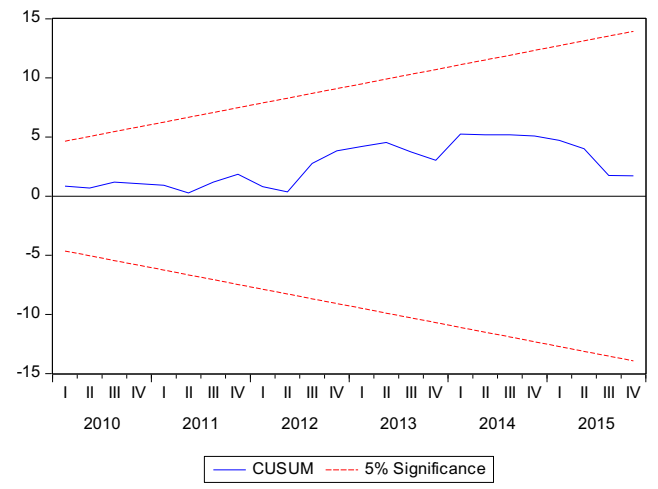

Şekil 6. CUSUM ve CUSUMSQ Testleri

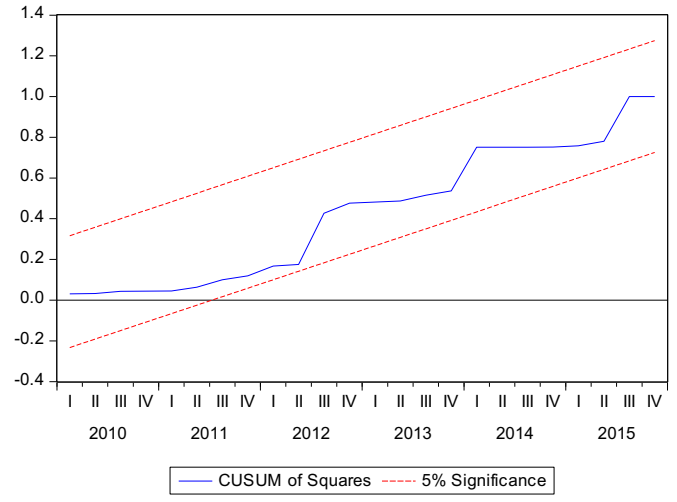

söyleyebiliriz. Dolayısıyla tahmin edilen ekonomik büyüme modeli politika belirlenmesi amacıyla kullanılabilir. Çünkü eşitlikteki parametreler tahmin döneminde istikrarlı bir seyir izlediğinden, büyüme modelinin açıklayıcı değişkenlerindeki politika değişikliklerinin etkileri milli gelir üzerinde büyük sıçramalar yaratmayacaktır.

Tablo 8. VAR Granger nedensellik/Blok Dışsallık Testi

\begin{tabular}{l|ccc}
\hline \multicolumn{4}{l}{ VAR Granger Nedensellik / Blok Dişsallık Wald Testi } \\
\hline Bağımlı Değişken : $L Y$ & Ki-Kare & Serbestlik Derecesi & Prob. \\
\hline \multicolumn{1}{c}{ Dışlanan } & 6,8896 & 2 & 0,0319 \\
\hline LTUR & 5,8611 & 2 & 0,0534 \\
Tümü & 11,0607 & 4 & 0,0259 \\
\hline
\end{tabular}

\begin{tabular}{lccc}
\hline Bağımlı Değişken : LTUR & & & \\
\hline \multicolumn{1}{c}{ Dışlanan } & Ki-Kare & Serbestlik Derecesi & Prob. \\
\hline$L Y$ & 2,9125 & 2 & 0,2331 \\
RER & 2,9849 & 2 & 0,2248 \\
& & & \\
Tümü & 7,0350 & 4 & 0,1340 \\
\hline
\end{tabular}


Son olarak değişkenler arasındaki nedensel ilişkilerin yönünü belirlemek amacıyla Toda Yamamoto yaklaşımı ile Granger nedensellik testi uygulanmıştır. Test için öncelikle maksimum bütünleşme derecesinin (dmax) belirlenmesi gerekmektedir. ADF ve PP birim kök testleri sonucunda LY ve LTUR serilerinin I(1); RER serisinin ise $\mathrm{I}(0)$ olarak belirlendiği hatırlanırsa, maksimum bütünleşme derecesi 1 olarak belirlenmiş olur. Daha sonra değişkenlerin düzey değerleri ile kısıtsız bir VAR modeli tahmin edilmiş ve model seçim kriterleri yardımı ile uygun gecikmenin 1 oldugu belirlenmiştir. $\mathrm{Bu}$ aşamadan sonra $\operatorname{VAR}(\mathrm{P}+\mathrm{dmax})$ yani $\operatorname{VAR}(1+1)$ modeli tahmin edilerek VAR Granger nedensellik/Blok dışsalık testi uygulanmıştır. Testin sonuçları Tablo 8'de sunulmaktadır.

VAR Granger nedensellik testi sonuçlarına göre Turist sayısından Milli gelire doğru nedensellik olmadığını ifade eden sıfır hipotezi $\% 5$ anlam düzeyinde reddedilmektedir (Prob $=0,0319$ ). Yani gelen turist milli gelirin artmasına ya da değişkenler doğal logaritmalarıyla kullanıldığından ekonomik büyümeye neden olmaktadır ( ). Diğer taraftan Milli Gelirden Turist sayısına doğru nedensellik olmadığını ifade eden sifır hipotezi ise $\% 5$ anlam düzeyinde reddedilememiştir. Yani milli gelirden turist sayısına doğru nedensellik yoktur. Bu durumda turizmden milli gelire doğru tek yönlü nedensellik olduğunu söyleyebiliriz. Granger nedensellik testi ile ulaştığımız sonuç ARDL modelinden elde ettiğimiz kısa ve uzun dönemde turizmin milli geliri pozitif yönde etkilediği bulgusunu da desteklemektedir.

\section{Sonuç}

Bacasız sanayi olarak da adlandırılan turizm en hızlı büyüyen ve en fazla gelir getiren sektörlerden birisidir. Turizm son dönemlerde, ulusal ve bölgesel ekonomiler arasında dünyanın en büyük sanayisi ve iş yaratıc1sı haline gelmiştir. Bu çalışmanın amacı, Autoregressive Distributed Lag (ARDL) sınır testi yaklaşımı ile Türkiye’de turizmin ekonomik büyüme üzerindeki etkisini incelemek ve böylece, turizme dayalı büyüme hipotezinin Türkiye için geçerli olup olmadığını test etmektir. Analizde 2003-2015 dönemine ait çeyrek dönemlik reel GSYH, ülkeye gelen uluslararası turist sayısı ve reel döviz kuru (RER) verileri kullanılmıştır. Reel GSYH ve gelen turist sayıları mevsimsellikten arındırıldıktan sonra doğal logaritmaları ile kullanıldıklarından, sonuçlar turizmin ekonomik büyümeye katkısı olarak yorumlanabilir. Elde edilen sonuçlara göre turizmin Gayrisafi Yurtiçi Hasıla üzerinde hem kısa dönemde hem de uzun dönemde anlamlı pozitif etkisi vardır. İkinci olarak Granger nedensellik testine Toda-Yamamoto yaklaşımı kullanılmış ve turizmden ekonomik büyümeye doğru tek yönlü bir nedensellik ilişkisi belirlenmiştir. Dolayısıyla çalışmadan elde edilen bu bulgular, Türkiye örneği için turizme dayalı büyüme hipotezinin ampirik olarak desteklendiğini göstermektedir. Bu sonuç, turizme dayalı büyüme hipotezinin Türkiye için geçerli olduğuna dair herhangi bir bulgu elde edemeyen Katırcıoğlu (2009b) ve Arslantürk vd. (2011)'in aksine; Gunduz ve Hatemi-J. (2005), Kaplan ve Çelik (2008), Zortuk (2009), Husein ve Kara (2011), Işık, (2012), Ertugrul ve Mangir (2015)'in ortaya koydukları bulgular ile örtüşmektedir.

Uluslararası turizm gelirleri, ihracat geliri yaratmas1nın yanında, önemli bir döviz kaynağı olduğundan; Türkiyede özellikle özel sektörün döviz borcunun arttığı dönemlerde turizm gelirlerinin istikrarlı olmas1, ekonomik istikrar ve büyümenin sürdürülebilmesi açısından son derece önemlidir. Ayrıca sanayi üretiminin yavaşladığ 1 dönemlerde turizmin istihdam yaratarak işsizlik sorununa çare olma potansiyeli de bulunmaktadır. Dünya Turizm Örgütüne göre, ülkelere göre ziyaretçi başına turizm gelirinde 2014 yılında dünya ortalaması 1.100 dolar iken Türkiye’ye gelen bir ziyaretçi ülkemize ortalama 828 dolar bırakmıştır (TÜIK, 2016). Türkiye'de kamu tarafından belirlenen 2023 yılı hedeflerine göre gelen turist sayısının yılda 50 milyona ulaşması ve turizm gelirinin 50 milyar dolar olması hedeflenmektedir. Bu durumda Türkiye’ye daha fazla turist çekilmesi için ziyaretçiler açısından istikrarlı ve sakin bir ortam yaratılması, turizme yönelik teşvik edici politikaların uygulanması ile turizm gelirleri daha da artırılabilecektir. Böylece turizm sektörünün ülkenin GSYH'sindeki payı ve dolayısıla ekonomik büyümeye yaptığı katkı daha da artacaktır.

$\mathrm{Bu}$ çalışmada turizmin ekonomik büyüme ile olan ilişkisi ele alınmıştır. Bu konuya ilişkin olarak gelecekte yapılabilecek çalışmalarda turizmin farklı makroekonomik değişkenler ile olan ilişkileri ya da çeşitli sektörlere katkıları ele alınabilir. 


\section{Kaynakça}

Ahiawodzi, A. K. (2013). Tourism earnings and economic growth in Ghana. British Journal of Economics, Finance and Management Sciences, 7(2), 187-202.

Akinboade, O. ve Braimoh, L. A. (2010). International tourism and economic development in South Africa: A Granger causality test. International Journal of Tourism Research, 12, 149-163.

Arslanturk, Y., Balcilar, M. ve Ozdemir, Z. A. (2011). Time-varying linkages between tourism receipts and economic growth in a small open economy. Economic Modelling, 28(1-2), 664-671.

Balaguer ve Cantavella-Jorda (2002). Tourism as a long-run economic growth factor: the Spanish case, Applied Economics, 34, 877-884.

Belloumi, M. (2010). The relationship between tourism receipts, real effective exchange rate and economic growth in Tunisia. International Journal of Tourism Research, 12(5), 550-560.

Brida, J. G., Cortes-Jimenez, I. ve Pulina M. (2014). Has the tourism-led growth hypothesis been validated? A literatüre review. Current Issues in Tourism, http://dx.doi.org/10.1080/13683500.2013.86 8414

Brida, J. G., Pereyra, S. J., Risso, W. A., Such-Devesa, M. J. ve Zapata-Aguirre, S. (2009). The tourism-led growth hypothesis: Empirical evidence from Colombia. Tourismos: An International Multidisciplinary Journal of Tourism, 4(2), 13-27.

Brida, J. G., Punzo, L. F. ve Risso, W. A. (2011). Tourism as a factor of growth: The case of Brazil. Tourism Economics, 17(6), 1375-1386.

Brida, J. G. ve Risso, W. A. (2009). Tourism as a factor of long-run economic growth: An empirical analysis for Chile. European Journal of Tourism Research, 2(2), 178-185.
Brown, R.L., Durbin, J., Evans, J.M., (1975). Techniques for testing the constancy of regression relations over time. Journal of the Royal Statistical Society, 37, 149-163.

Corrie, K., Stoeckl, N. ve Chaiechi, T. (2013). Tourism and economic growth in Australia: an empirical investigation of causal links. Tourism Economics, 19(6), 1317-1344.

Cortes-Jimenez, I. ve Pulina, M. (2010). Inbound tourism and long run economic growth. Current Issues in Tourism, 13(1), 61-74.

Coşkun, İ.O. ve Özer, M. (2014). A Reexamination of the Tourism-Led Growth Hypothesis Under Growth and Tourism Uncertainties in Turkey. European Journal of Business and Social Sciences, Vol. 3(8), 256-272.

Çağlayan, E. (2006). Enflasyon, Faiz Oranı ve Büyümenin Yurtiçi Tasarruflar Üzerindeki Etkileri, Marmara Üniversitesi İ.İ.B.F. Dergisi, XXI(1).

Dolado, J. J. ve Lütkepohl, H., (1996). Making wald tests work for cointegrated VAR systems. Econometric Reviews, 15, 369-386.

Dritsakis, N. (2004). Tourism as a long-run economic growth factor: An empirical investigation for Greece using causality analysis. Tourism Economics, 10(3), 305-316.

Engle, R.F. ve C.W.J. Granger (1987). Co-integration and Error Correction Estimation and Testing, Econometrica, 55, 251-276.

Ertugrul H. M. ve Mangir F. (2015). The tourism-led growth hypothesis: empirical evidence from Turkey, Current Issues in Tourism, 18 (7), 633-646.

Granger, C.W.J. (1969). Investigating causal relation by econometric and cross-sectional method, Econometrica, 37, 424-438. 
Granger, C.W.J. (1988). Some recent developments in the concept of causality, Journal of Econometrics, 39, 199-211.

Gunduz, L. ve Hatemi-J, A. (2005). Is the tourism-led growth hypothesis valid for Turkey? Applied Economics Letters, 12 (8), 499-504.

Husein, J. ve Kara, S. M. (2011). Research note: Reexamining the tourism-led growth hypothesis for Turkey. Tourism Economics, 17(4), 917-924.

Işık, C. (2012). The USA's international travel demand and economic growth in Turkey: A causality analysis: (1990-2008). Tourismos: An International Multidisciplinary Journal of Tourism, 7(1), 235-252.

Jackman, M. (2012). Revisiting the tourism-led growth hypothesis for Barbados: A disaggregated market approach. Regional and Sectoral Economic Studies, 12(2), 15-26.

Jalil, A., Mahmood, T. ve Idrees, M. (2013). Tourismgrowth nexus in Pakistan: Evidence from ARDL bounds tests, Economic Modelling, 35(C), 185-191.

Jayathilake, P. M. B. (2013). Tourism and economic growth in Sri Lanka: Evidence from cointegration and causality analysis. International Journal of Business, Economics and Law, 2(2), 22-27.

Johansen, S. (1988). Statistical Analysis of Cointegration Vectors, Journal of Economic Dynamics and Control, 12(2-3), 231-254.

Johansen, S. (1991). Estimation and Hypothesis Testing of Cointegration Vectors in Gaussian Vector Autoregressive Models, Econometrica, 59(6), 15511580.

Johansen, S. ve Juselius K. (1990). Maximum Likelihood Estimation and Inference on Cointegration with Applications to the Demand for Money. Oxford Bulletin of Economics and Statistics, 52(2), 169210.
Kaplan, M. ve Çelik, T. (2008). The impact of tourism on economic performance: The case of Turkey. The International Journal of Applied Economics and Finance, 2(1), 13-18.

Kasimati, E. (2011). Economic impact of tourism on Greece's economy: Cointegration and causality analysis. International Research Journal of Finance and Economics, 79, 79-85.

Katırcioglu, S. T. (2009a). Testing the tourism-led growth hypothesis: The case of Malta. Acta Oeconomica, 59(3), 331-343.

Katircioglu, S. T. (2009b). Revising the tourism-ledgrowth hypothesis for Turkey using the bounds test and Johansen approach for cointegration. Tourism Management, 30, 17-20.

Katircioğlu, S. T. (2010). International tourism, higher education and economic growth: The case of North Cyprus. The World Economy, 33(12), 1955-1972.

Katırcıoğlu, S. T. (2011). Tourism and Growth in Singapore. New extension from bounds test to level relationship and conditional Granger causality tests. Singapore Economic Review, 56(3), 441-453.

Kim, H. J., Chen, M.-H. ve Jang, S. C. S. (2006). Tourism expansion and economic development: The case of Taiwan. Tourism Management, 27, 925-933.

Kostakoğlu, S. F. (2016). Sanayi Sektörü İş Hacminin Ekonometrik Analizi. Anadolu Üniversitesi Sosyal Bilimler Dergisi, 16(2), 61-68.

Kreishan, F. M. (2011). Time-series evidence for tourism-led growth hypothesis: A case study of Jordan. International Management Review, 7(1), 89-93.

Mishra, P. K., Rout, H. B. ve Mohapatra, S. S. (2011). Causality between tourism and economic growth: Empirical evidence from India. European Journal of Social Sciences, 18(4), 518-527. 
Oh, C. K. (2005). The contribution of tourism development to economic growth in the Korean economy. Tourism Management, 26 (1), 39-44.

Ongan, S. ve Demiröz, D. M. (2005). The contribution of tourism to the long-run Turkish economic growth. Ekonomicky Casopis (Journal of Economics), 53(9), 880-894.

Payne, J. E. ve Mervar, A. (2010). The tourism-growth nexus in Croatia. Tourism Economics, 16(4), 10891094.

Pesaran, M.H. ve Pesaran, B., (1997). Working with Microfit 4.0. Interactive Econometric Analysis. Oxford University Press, Oxford.

Pesaran, M.H. ve Shin, Y. (1999). An Autoregressive Distributed Lag Modelling Approach to Cointegration Analysis, in (ed) S.Storm, Econometrics and Economic Theory in the 20th Century. The Ragnar Frisch Centennial Symposium, chapter11, Cambridge Univ. Press, Cambridge. (http://www.econ. cam.ac.uk/faculty/pesaran/ardl.pdf).

Pesaran M.H., Shin Y. ve Smith R. (2001). Bounds Testing Approaches to the Analysis of Level Relationship, Journal of Applied Econometrics, 16(3), 289-326.
Srinivasan, P. K., Kumar, S. ve Ganesh, L. (2012). Tourism and economic growth in Sri Lanka: An ARDL bounds testing approach. The Romanian Economic Journal, 45, 211-226.

Tang, C. F. (2013). Temporal Granger causality and the dynamic relationship between real tourism receipts, real income, real exchange rates in Malaysia. International Journal of Tourism Research, 15(3), 272-284.

Tang, C. F., ve Abosedra, S. (2014). Small sample evidence on the tourism-led growth hypothesis in Lebanon. Current Issues in Tourism, 17(3), 234-246.

Toda, H. Y ve Yamamoto, T. (1995). Statistical inferences in vector autoregressions with possibly integrated processes. Journal of Econometrics, 66, 225-250.

TÜİK (2016). Basın Odası Haberleri, Sayı: 16/2016, 10 Şubat 2016.

UNWTO (2015). Tourism Highlights, 2015 Edition.

Zortuk, M. (2009). Economic impact of tourism on Turkey's economy: Evidence from cointegration tests. International Research Journal of Finance and Economics, 25, 231-239. 